\title{
A qualitative study on aspects of consent for genomic research in communities with low literacy
}

Daima Bukini ${ }^{1 *} \mathbb{D}$, Columba Mbekenga ${ }^{2}$, Siana Nkya ${ }^{1}$, Lisa Purvis ${ }^{3}$, Sheryl McCurdy ${ }^{4}$, Michael Parker ${ }^{5}$ and Julie Makani ${ }^{1}$

\begin{abstract}
Background: Low literacy of study participants in Sub - Saharan Africa has been associated with poor comprehension during the consenting process in research participation. The concerns in comprehension are far greater when consenting to participate in genomic studies due to the complexity of the science involved. While efforts are made to explore possibilities of applying genomic technologies in diseases prevalent in Sub Saharan Africa, we ought to develop methods to improve participants' comprehension for genomic studies. The purpose of this study was to understand different approaches that can be used to seek consent from individuals with low literacy in Sub-Saharan African countries in genomic research to improve comprehension.

Methods: Using qualitative study design, we conducted focus-group discussions, in-depth interviews and participant observations as data collection methods. This study was embedded in a hospital based genomic study on Sickle Cell Disease at Muhimbili National Hospital in Tanzania. Thematic content analysis was used to analyse the transcripts and field notes.

Results: Findings from this study show that literacy level has little influence on understanding the research details. According to the participants of this study, the methods used to provide information, the language, and time spent with the study participants were the key factors influencing understanding. The availability of group sessions held before individual consent to allow for a detailed questions and answers format was agreed to be the best method to facilitate the comprehension.

Conclusion: The quality of the consenting process of participants will be influence by a number of factors. The type of research consented for, where the research will be implemented and who are the potential study participants are amongst the factors that need to be assessed during the consenting. Measures to improve participants' comprehension need to be developed when consenting participants with low literacy level in genomic studies.
\end{abstract}

Keywords: Informed consent, Comprehension, Low literacy, Genomic studies

\footnotetext{
* Correspondence: daimabukini@gmail.com; dathuman@muhas.ac.tz

${ }^{1}$ Sickle Cell Programme, Department of Haematology and Blood Transfusion,

Muhimbili University of Health and Allied Sciences, UN Road, Upanga, Block

9, Dar es Salaam, Tanzania

Full list of author information is available at the end of the article
}

(c) The Author(s). 2020 Open Access This article is licensed under a Creative Commons Attribution 4.0 International License, which permits use, sharing, adaptation, distribution and reproduction in any medium or format, as long as you give appropriate credit to the original author(s) and the source, provide a link to the Creative Commons licence, and indicate if changes were made. The images or other third party material in this article are included in the article's Creative Commons licence, unless indicated otherwise in a credit line to the material. If material is not included in the article's Creative Commons licence and your intended use is not permitted by statutory regulation or exceeds the permitted use, you will need to obtain permission directly from the copyright holder. To view a copy of this licence, visit http://creativecommons.org/licenses/by/4.0/ The Creative Commons Public Domain Dedication waiver (http://creativecommons.org/publicdomain/zero/1.0/) applies to the data made available in this article, unless otherwise stated in a credit line to the data. 


\section{Background}

One of the requirements for conducting ethical research with competent adult participants is obtaining a valid informed consent [1-3]. Studies have suggested that designing and obtaining consent for genomic studies when implemented in Sub-Saharan Africa (SSA) is challenging to the researchers and research participants [4-8]. Often low literacy of the participants has been associated with poor comprehension during the consenting process $[9$, 10]. The challenges are linked to difficulties in providing information in a comprehensible manner to the participants considering the complexity of the science involved $[11,12]$. The process of interpretations and translations of key concepts into accessible terms for the participants can be challenging to achieve for researchers and field workers $[6,13]$. This is particularly problematic in populations where the science requires translations into local languages $[2,14-16]$. Lack of training in genetics for clinicians and the shortage of genetic counsellors in the SSA may have increased the difficulty in communicating the information to the research participants [17]. Often in this context, a well-written and signed consent by a participant does not guarantee understanding. In contributing to that discussion, we designed an exploratory study aiming to understand research participants' perspectives and experiences when consented in a genomic study implemented in SSA. We were particularly interested to learn how participants' literacy level may have had an influence on their understanding the details of the research into which they have enrolled.

\section{Methods}

\section{Sampling and recruitment}

We recruited research participants enrolled in an urban hospital-based study aiming to understand genetic determinants of clinical heterogeneity of sickle cell disease (SCD) in Tanzania [18, 19]. At the time of recruitment, the study consisted of 3751 individuals with SCD, 1779 were between 5 and 17 years of age with almost a 50/50 gender distribution [20]. Participants for the study reported here, were recruited through adult and paediatric clinics at Muhimbili National Hospital. Purposive sampling was used to select individuals willing to provide detailed information about their understanding and experiences of being enrolled in the study. In total forty-three $(n=43)$ participants were recruited into our study. We defined literacy level in relation to the number of years spent in school as per the education system in Tanzania; (1) Primary - basic level of education, also included here were participants with no formal education $(n=$ 23); (2) Secondary level - intermediate level $(n=16)$; and (3) Tertiary level - high level of education $(n=4)$.

\section{Data collection methods}

Data was collected through focus-group discussions (FGDs), in-depth interviews (IDIs) and participant observations (POs).

\section{Focus group discussions (FGDs)}

Five FGDs were conducted with six participants in each of the groups. The composition of the FGDs took into consideration age, level of education, and gender. The FGD guide was designed to facilitate a semi-structured discussion around participants' experiences, challenges and possible ways to improve the consenting process. In total, 30 individuals participated in the five FGDs. Participants included were adult SCD patients enrolled in the study. Details of the participants' descriptions are provided in Table 1.

\section{Participant observations and in depth interviews}

In addition to the focus groups, we observed the consent process of six new participants who were enrolled in the study during the period of our research. The content of the observation checklist was developed based on the consent form used by the researchers. For instance, we observed how the researcher communicated the objectives and methods of the study to the participants as described in the informed consent. After observing the consenting process, we interviewed those participants (IDIs) to gather their perspectives on the consenting process. In total, 13 IDIs were conducted, out of which seven (7) IDIs were conducted with research participants who were already enrolled in the study. Amongst the participants, nine were parents of children who have been enrolled in the SCD study. Participants were aged 24 to 43 years old, amongst which two (2) were men and eleven (11) women. Since most of the children were brought to the clinic by their mothers, we did end up interviewing more women than men in the study. Details of the participants' descriptions are provided in Table 2.

\section{Data analysis}

We analysed the transcripts and field notes using thematic content analysis adapted from another qualitative study implemented in Tanzania, Ghana and Cameroon

Table 1 Focus Group Discussions Participants

\begin{tabular}{ll}
\hline Description & Participants $(N=30)$ \\
\hline Male $\mathrm{n}(\%)$ & $7(23)$ \\
Age mean (min, max) & $26(18,40)$ \\
Education $n(\%)$ & \\
$\quad$ No formal education & $5(17)$ \\
Primary education- basic level of education & $9(30)$ \\
Secondary education- intermediate & $12(40)$ \\
Tertiary education- high level of education & $4(13)$ \\
\hline
\end{tabular}


Table 2 In Depth Interviews participants

\begin{tabular}{ll}
\hline Male $\mathrm{n}(\%)$ & $2(13)$ \\
Age mean (min, max) & $33(24,43)$ \\
Education $n$ (\%) & \\
No formal education & $3(13)$ \\
Primary & $6(35)$ \\
Secondary & $4(23.5)$ \\
Tertiary & $0(0)$ \\
\hline
\end{tabular}

[21]. The first author, (DB), collected all the information for IDIs and FGDs as well as recording participants' observation checklist. The interviews were all done in Swahili and then translated to English after the analysis stage. After the initial coding by DB, co-authors CM and SM completed quality checks by reviewing a selection of the data. The themes were developed inductively, based on the emerging codes. Sorting and coding were continued until no new subcategories could be identified from the data. Data from all three methods were analysed together to check for similarities or differences. The emergent themes are results of the analysis of all methods: IDIs, FGDs and POs.

\section{Results}

Three main themes were identified from our analysis of the data from FGDs, IDIs and POs: 1) Relationship between low levels of literacy and the achievement of informed consent; (2) Factors contributing to poor understanding included: inadequate information provided to the participants, age at enrolment, and time spent by the participants; (3) Possible ways to improve understanding as suggested by participants; opportunities to ask questions and group information sessions followed by individual consenting.

\section{The relationship between low levels of literacy and the achievement of informed consent}

Participants who reported having no formal education and those categorized as having low literacy felt that the possibility of gaining a good understanding of the research was not influenced by having low literacy level. This perception was consistent during the IDIs, FGDs and POs. The following quotations illustrate this.

A response from a mother (IDI 3) who doesn't know how to read or write was, "Research in Sickle Cell Disease are [is] done to understand the cure and find solutions on this problem" IDI 3, interview with a mother of a child with SCD enrolled in the genomic study
Another example was also from a mother (IDI 1) who has not received formal education, she explained, "Research is an investigation to understand about a certain disease problem in-depth or look for a cure of a certain disease"' IDI 1, interview with a mother of a child with SCD enrolled in the genomic study

In one of the FGDs, participants were asked whether the information provided by researchers was easy or difficult to understand. One FGD member began,

"Yes, it is easy to understand, [A probe was followed after his response, Is it easy for you because you are a college graduate? ] Another participant in the group with no formal education replied, "It is all about the individual person and has nothing to do with the level of education" focus group discussion 2 with adult SCD patients enrolled in the genomic study

A participant in another FGDs claimed, "I am not concerned by the type of information provided, it is not a problem for me to understand, we need to be educated more on the research and understanding will not be a problem" focus group discussion 3 with adult SCD patients enrolled in the genomic study

A few participants believed that education plays a major role to be able to understand the information.

One noted, "It is true that for someone to understand this (research) information, it will depend on the individual person, but also the level of education they possess" IDI participant 5, 43 year-old men with SCD who was newly enrolling in the genomic study

\section{Factors contributing to poor comprehension of the research}

Adequacy of the information provided to the participants The majority of participants for both the IDIs and FGDs felt that research information was not adequately provided. Participants describe the quality of the interactions,

\footnotetext{
"You need more time to understand the information and if you are not keen enough you will not be able to understand, time given was so short and answers were given in a rush [ed] way" IDI participant 9, mother of a child with SCD enrolled in the genomic study
}

A FGDs respondent clarified, "The truth is we are not getting enough information from the doctors [researchers] and education is not being provided to our satisfaction [on the research], only the progress of your disease, but nothing more...that is at least my personal view" Focus group discussion 1 with adult SCD patients enrolled in the genomic study 
One explanation the participants gave for why they had received inadequate information was an increase in patient load in the clinics, "I do not think we are now getting information as it used to be, as time goes by the number of clinic visits decreased and the time to stay with a doctor also has decreased" Focus group discussion 2 with adult SCD patients enrolled in the genomic study

In contrast to the other study participants, however, one woman noted, "I have been provided with detailed information about the research, they have even come to my house to do research and the experience at home was quite good" IDI 7, interview with a mother of a child with SCD enrolled in the genomic study.

\section{Age at enrollment}

Age at enrolment was considered to be a factor by some of the participants for not recalling the information provided during the consenting process. Since participants were recruited from a cohort study, this was only relevant for those who were enrolled in the study by their parents or caretakers when they were young. As commented by one participant in the FGD,

"Time has passed since the last time we were enrolled, I cannot recall if it was difficult or easy to understand, maybe there is a need to be given the information again" focus group discussions 5 with adult SCD patients enrolled in the genomic study

Another participant, who was about 16 when enrolled [he was 19 at the time of the interview], recalled: "I remember my father signing this form [indicating the consent forms], but I was there to witness. I was about 16 years old. I remember my father looking satisfied with the information provided by the doctor. I do not recall being given the forms to go back home and read them" IDI participant 11, 19 year-old boy with SCD enrolled in the SCD genomic study

\section{Time the researcher spent with the study participants}

Participants felt that time spent with the researcher was not enough for detailed conversation. They were concerned that the time limitations do not allow them to ask questions.

"Maybe it's contributed [time spent] to the increase in number of people attending clinics these days, there is no time to listen to the patients one by one, and sometimes the environment is not that comfortable to start asking questions [Another participant in the same FGD clarified], It is like this [commanding people to listen to what she was about to say], before you even come out, another patient is already at the door waiting for you to come out or sometimes standing inside the room waiting, you cannot ask anything" focus group discussions 4 with adult SCD patients enrolled in the grnomic study

\section{Possible way to improve understanding during the consenting process \\ Opportunity to ask questions enhances participants' comprehension}

Participants who had opportunities to ask questions, recall how it helped them to understand the details of the research.

"We were given opportunities to ask questions, doctors I recall responded very well and we were satisfied, I am now confident that I have a fairly good understanding of the disease" IDI 6, interview with a mother of a child with SCD enrolled in the genomic study

"For those who are upfront they can ask questions to the doctors but the doctors they just do not start to provide explanation, for example, the tests we are doing at the clinic, [it is not] until you ask what are they for and what do these results mean [that you are given an explanation]" focus group discussions 3 with adult SCD patients enrolled in the genomic study

\section{Group information sessions followed by individual consenting}

Participants preferred group informational sessions followed up by individual meetings for signing the consent forms. For example, a woman in one FGD noted she preferred a group session,

"[That would be] like this [indicating the group discussions], in the presence of doctors ... because it can be very difficult to ask questions through the one to one method with a doctor ... some people feel ashamed to ask questions but in the group discussions you do not feel that" focus group discussions 4 with adult SCD patients enrolled in the genomic study

Another participant recalled, "We were provided the information in groups of five people and I think it helped to remember, although we both signed individually" focus group discussions 1 with adult SCD patients enrolled in the genomic study

In addition to preferring a two-stage general informational session and an individual consent signing process, participants preferred face-to-face encounters to getting 
information from a video, this comment was raised when participants were asked about having videos in the clinics to explain the study,

"I am sceptical with the video method of providing information, I am not sure of it, it depends on the research type, you just cannot show everything" focus group discussions 1 with adult SCD patients enrolled in the genomic study

\section{Discussion}

When we began this research, we expected low literacy to be one of the factors hindering comprehension at the time of consent to participate in genomic research. However, our findings and the analysis of our data have shown that participants believe that understanding of the concepts in genomic research were dependent more on the methods used to communicate the information [22]. These results were similar to those of a study conducted in Gambia and Bangladesh [10, 23, 24] which indicated that ways in which information is provided is the most important component influencing success of the consenting process.

Limitation of time was also a contributing factor for researchers not to adequately provide information. Group interactions were thought by participants as very helpful to assist them recall the information and provided them with opportunities to ask any questions they have to the doctors as compared to the one-on-one session. In addition to that, the group sessions before one-to-one sessions will help minimize time the researchers will spend with individual participant to explain the research.

Although participants acknowledged that asking questions can enhance comprehensions, only few participants felt comfortable asking questions about the research. Fear of being seen as ignorant, trusting that doctors know it all and the power imbalance between the researcher and the subject especially when the doctor is also the one recruiting subjects limit participants willingness to ask questions [14, 25-27]. One way of addressing this is might be by having the research team different from the clinical team.

Participants who enrolled in the study when they were young could not recall the information provided during the consenting process. Some vaguely recall their parents consenting on their behalf. This explains the importance of re-consenting study participants after a certain time period depending on the study's risk level and duration. The re-consenting process emphasized is not just asking participants if they are willing to continue being part of the study, but rather refreshing on the purpose of the study, procedures involved, risks as well as benefits of the research.
In our interviews and focus groups, in addition to highlighting challenges, participants suggested alternate research presentation methods that could be used to improve the effectiveness and accessibility of consent processes. Suggestions made included the use of practical examples and simple terminologies that can be easily understood by the participants [28, 29]. Participants in this study felt that the quality of the information provided was compromised by the limited time doctors have to spend on the consenting process. It was felt that providing information in groups through seminars, in the presence of nurses or doctors as moderators, would help to save time required during the one-on-one session. In-group sessions, the researcher may try to ensure all the general components of the informed consent such as purpose, risks, procedures, benefits and dissemination plans are explained in detail [30]. By using a group session approach, researchers who may also be physicians, will not be required to spend a lot of time explaining research to individual participants. This particular arrangement will not substitute individual autonomy because the aim will be to empower the subjects to make the right informed decision, after understanding the study details. This is also supported by a study done on tailoring consent to context [23], that in some settings individual consent may benefit from being preceded with providing information in groups. However, there are studies that suggested that there were no overall benefits of providing information in groups before individual consent [31].

Since this study was done in a hospital setting, participants sometimes seem to confuse research methods and clinical practices. At times it was difficult to tell whether the experiences they were referring to, were research or clinical experiences. We also acknowledge that the experiences shared by participants in this study do not seem to be specific to genomic research, and, therefore, the findings can be broadly interpreted to other nongenomic research.

\section{Conclusion}

This study afforded us with an opportunity to reflect on what kind of information is being provided to the participants and how. Our findings suggest that the reason why comprehension is difficult is not solely due to low literacy of the participants but also, perhaps mostly, down to how the information is being provided. Researchers conducting research in the low-literacy settings have to invest in understanding the best methods to use to provide the research information in a much more accessible and comprehensible manner. Participants' low literacy levels have always been used as a scapegoat for poor comprehension, but by placing the blame on participants we have failed to acknowledge our failure to consider the context and adequately provide 
clear explanations of our research. Our recommendation to researchers is to plan the consenting process ahead of time and plan for a re-consenting phase for studies that have a long time span, to factor in the context of where the research will be carried out, and to better understand the needs of the target population to and align their needs to efforts to fully inform the consenting process. However, we do acknowledge that participants recruited in this study may have different consenting experiences due to several factors at the time of enrolment. Those factors may have largely contributed to their own perspectives on understanding of the research.

\section{Abbreviations}

SCD: Sickle Cell Disease; SSA: Sub Saharan Africa; FGDs: Focus Group

Discussions; IDIs: In- Depth Interviews; POs: Participant Observations

\section{Acknowledgements}

We thank parents and patients who have participated in this research, the Sickle Cell Programme, Department of Haematology and Blood Transfusion at Muhimbili University of Health and Allied Sciences and the Muhimbili National Hospital. We also thank Dr. Deogratius Soka and Sr. Rehema Nkingi who facilitated our research at the Sickle Cell Disease Clinic of Muhimbili National Hospital.

\section{Authors' contributions}

DB and JM conceived the study and participated in its design. DB interacted with the participants, performed interviews, transcriptions, and translations and the initial analysis. DS and RN assisted with the data collection and reviewing of the manuscript CM and SM. Assisted in the review of the analysis and the coding scheme and reviewing the manuscript. LP, SN, MP assisted in revising the manuscript. All authors reviewed and approved the final manuscript.

\section{Funding}

DMRET and SPARCO grant supported the research costs of this study. Commonwealth Scholarship supported my one-year studentship at the Ethox Centre at the University of Oxford where further analysis and writing of the work was done.

\section{Availability of data and materials}

The datasets used and analysed during the current study are available from the corresponding author on reasonable request.

\section{Ethics approval and consent to participate}

The study was approved by the MUHAS Research Ethics Committee. Written consent was sought from the participants prior to the conduct of the study. The study involved research participants who are 18 years and older to ensure that all participants have reached the legal age to consent.

\section{Consent for publication}

Not applicable.

\section{Competing interests}

The authors declare that no conflicting financial interests exist.

\section{Author details}

'Sickle Cell Programme, Department of Haematology and Blood Transfusion, Muhimbili University of Health and Allied Sciences, UN Road, Upanga, Block 9, Dar es Salaam, Tanzania. ${ }^{2}$ School of Nursing and Midwifery, Aga Khan University, Dar es Salaam, Tanzania. ${ }^{3}$ The Dartmouth Institute for Health Policy \& Clinical Practice, Dartmouth-Hitchcock Medical Centre, Hanover, NH, USA. ${ }^{4}$ University of Texas Health Science Centre at Houston, School of Public Health, Houston, TX, USA. ${ }^{5}$ Welcome Centre for Ethics and Humanities, University of Oxford, Oxford, UK.
Received: 19 November 2019 Accepted: 2 June 2020

Published online: 12 June 2020

\section{References}

1. Council for International Organizations of Medical Sciences (CIOMS). International Ethical Guidelines for Health-related Research Involving Humans. 2016.

2. Emanuel EJ, Wendler D, Grady C. What makes clinical research ethical? JAMA. 2015. https://doi.org/10.1001/jama.283.20.2701.

3. Holm S. Declaration of Helsinki. In: International Encyclopedia of Ethics; 2013.

4. Chokshi DA, Thera MA, Parker M, Diakite M, Makani J, Kwiatkowski DP, et al. Valid consent for genomic epidemiology in developing countries. PLoS Med. 2007;4:e95. https://doi.org/10.1371/journal.pmed.0040095.

5. Kegley JAK. Challenges to informed consent. EMBO Rep. 2004. https://doi. org/10.1038/sj.embor.7400246.

6. Marshall PA, Adebamowo CA, Adeyemo AA, Ogundiran TO, Strenski T, Zhou $J$, et al. Voluntary participation and comprehension of informed consent in a genetic epidemiological study of breast cancer in Nigeria. BMC Med Ethics. 2014;15:38.

7. Munung NS, Marshall P, Campbell M, Littler K, Masiye F, Ouwe-Missi-OukemBoyer $\mathrm{O}$, et al. Obtaining informed consent for genomics research in Africa: analysis of H3Africa consent documents. J Med Ethics. 2016;42(2):132-7.

8. Molyneux S, Bull S. Consent and community engagement in diverse research contexts: reviewing and developing research and practice. J Empir Res Hum Res Ethics. 2013. https://doi.org/10.1525/jer.2013.8.4.1.

9. Nyika A. Ethical and practical challenges surrounding genetic and genomic research in developing countries. Acta Trop. 2009;112(Suppl 1):S21-31..

10. Lynöe N, Hyder Z, Chowdhury M, Ekström L. Obtaining informed consent in Bangladesh. N Engl J Med. 2001;344:460-1. https://doi.org/10.1056/ NEJM200102083440617.

11. McGuire AL, Beskow LM. Informed Consent in Genomics and Genetic Research. Annu Rev Genomics Hum Genet. 2010;11:361-81.

12. Molyneux CS, Peshu N, Marsh K. Understanding of informed consent in a low-income setting: three case studies from the Kenyan coast. Soc Sci Med. 2004:59:2547-59.

13. Moodley K, Pather M, Myer L. Informed consent and participant perceptions of influenza vaccine trials in South Africa. J Med Ethics. 2005;31:727-32.

14. Afolabi MO, Okebe JU, Mcgrath N, Larson HJ, Bojang K, Chandramohan D. Informed consent comprehension in African research settings. Trop Med Int Health. 2014;19(6):625-42.

15. Papanikolaou KA, Mabbott A, Bull S, Grigoriadou M. Designing learnercontrolled educational interactions based on learning/cognitive style and learner behaviour. Interact Comput. 2006. https://doi.org/10.1016/j.intcom. 2005.11.003.

16. Tindana P, Bull S, Amenga-Etego L, De Vries J, Aborigo R, Koram K, et al. Seeking consent to genetic and genomic research in a rural Ghanaian setting: a qualitative study of the MalariaGEN experience. BMC Med Ethics. 2012;3:15.

17. Wonkam A, Angwafo FF. Prenatal diagnosis may represent a point of entry of genetic science in sub-Saharan Africa: a survey on the attitudes of medical students and physicians from Cameroon [8]. Prenat Diagn. 2006; 26(8):760-1.

18. Mtatiro SN, Singh T, Rooks H, Mgaya J, Mariki H, Soka D, et al. Genome wide association study of fetal hemoglobin in sickle cell anemia in Tanzania. PLoS One. 2014:99(11):e1 11464. https://doi.org/10.1371/journal.pone.0111464.

19. Mtatiro SN, Mgaya J, Singh T, Mariki H, Rooks H, Soka D, et al. Genetic association of fetal-hemoglobin levels in individuals with sickle cell disease in Tanzania maps to conserved regulatory elements within the MYB core enhancer. BMC Med Genet. 2015;16:4.

20. Makani J, Tluway F, Makubi A, Soka D, Nkya S, Sangeda R, et al. A ten year review of the sickle cell program in Muhimbili national hospital. Tanzania. https://doi.org/10.1186/s12878-018-0125-0.

21. Bukini D, deVries J, Treadwell M, Anie K, Dennis-Antwi J, Kamga KK, et al. Exploring the Role of Shared Decision Making in the Consent Process for Pediatric Genomics Research in Cameroon, Tanzania, and Ghana. AJOB Empir Bioeth. 2019:1-8. https://doi.org/10.1080/23294515.2019.1645759.

22. Bull S, Farsides B, Ayele FT. Tailoring information provision and consent processes to research contexts: the value of rapid assessments. J Empir Res Hum Res Ethics. 2012;7(1):37-52. 
23. Tekola F, Bull SJ, Farsides B, Newport MJ, Adeyemo A, Rotimi CN, et al. Tailoring consent to context: designing an appropriate consent process for a biomedical study in a low income setting. PLoS Negl Trop Dis. 2009;3(7): e482.

24. Campbell MM, Susser E, Mall S, Mqulwana SG, Mndini MM, Ntola OA, et al. Using iterative learning to improve understanding during the informed consent process in a south African psychiatric genomics study. PLoS One. 2017;12:1-11.

25. Fitzgerald DW, Marotte C, Verdier Rl, Johnson WD, Pape JW. Comprehension during informed consent in a less-developed country. Lancet. 2002;360: $1301-2$.

26. Afolabi MO, Bojang K, D'Alessandro U, Ota MOC, Imoukhuede EB, Ravinetto $\mathrm{R}$, et al. Digitised audio questionnaire for assessment of informed consent comprehension in a low-literacy African research population: development and psychometric evaluation. BMJ Open. 2014:4(6):e004817.

27. Gikonyo C, Bejon P, Marsh V, Molyneux S. Taking social relationships seriously: lessons learned from the informed consent practices of a vaccine trial on the Kenyan coast. Soc Sci Med. 2008;67(5):708-20.

28. Jefford M, Moore R. Improvement of informed consent and the quality of consent documents. Lancet Oncol. 2008;9(5):485-93.

29. Tariq S, Woodman J, Mexas F, Efron A, Luiz RR, Cailleaux-Cezar M, Chaisson RE, et al. Improving informed consent: stakeholder views. Genet Med. 2014. https://doi.org/10.1016/j.coviro.2015.09.001.Human

30. Cohn E, Larson E. Improving participant comprehension in the informed consent process. J Nurs Scholarsh. 2007;39(3):273-80.

31. Sarkar R, Sowmyanarayanan TV, Samuel P, Singh AS, Bose A, Muliyil J, et al. Comparison of group counseling with individual counseling in the comprehension of informed consent: a randomized controlled trial. BMC Med Ethics. 2010;11:8.

\section{Publisher's Note}

Springer Nature remains neutral with regard to jurisdictional claims in published maps and institutional affiliations.

Ready to submit your research? Choose BMC and benefit from:

- fast, convenient online submission

- thorough peer review by experienced researchers in your field

- rapid publication on acceptance

- support for research data, including large and complex data types

- gold Open Access which fosters wider collaboration and increased citations

- maximum visibility for your research: over $100 \mathrm{M}$ website views per year

At BMC, research is always in progress.

Learn more biomedcentral.com/submissions 